\title{
A Novel Test Method to Determine the Wear Resistance of Agricultural Cutting Tools with an Analyzing Method Based on an Ellipse-Fit Algorithm
}

\author{
Andreas Jahr, Robert Bongartz, Hunn Sim, and Alex Pillmann \\ FMDauto, University of Applied Sciences Düsseldorf, Josef-Gockel-Strasse 9, 40474 Düsseldorf, Germany \\ Correspondence should be addressed to Hunn Sim; hunn.sim@fh-duesseldorf.de
}

Received 1 August 2014; Revised 18 December 2014; Accepted 22 December 2014

Academic Editor: Michael Moseler

This Conference Paper is based on a presentation given by Hunn Sim at "European Symposium on Friction, Wear, and Wear Protection" held from 6 May 2014 to 8 May 2014 in Karlsruhe, Germany.

Copyright (C) 2015 Andreas Jahr et al. This is an open access article distributed under the Creative Commons Attribution License, which permits unrestricted use, distribution, and reproduction in any medium, provided the original work is properly cited.

\begin{abstract}
Cutting belongs to the essential techniques in many fields of application in agricultural engineering. Cutting tools in agriculture are exposed to a high amount of abrasive wear and impact stress. Increasing the wear resistance of cuttings tools has a high significance for the efficiency and profitability of agricultural machinery. Blunt and deformed blades decrease the energy efficiency and the cutting quality. Blade failures cause machine breakdowns and increase labor and material costs. To enable a consistent and systematic optimization of the blades, a suitable testing method is necessary. Conventional field tests do not provide comparable and repeatable results. Therefore, a test method developed at the FMDauto in cooperation with the Ennepetaler Schneid- und Mähtechnik (ESM) GmbH \& Co. KG is presented. The test bench provides standardized and repeatable conditions with a similar wear pattern which is found during field operations. One of the remaining challenges is a clear wear characterization. Existing analyzing methods do not consider the energy efficiency and do not determine the edge holding property clearly. In this paper, a new analyzing method based on an ellipse-fit method is introduced to rate the geometrical shape of the cutting edge and examine the wear resistance of different blades.
\end{abstract}

\section{Introduction}

The growing world population evokes a steadily increasing demand for food and energy. $90 \%$ of the world production area is already cultivated. An extensive yield increase is necessary to ensure the increasing demand for food and biomass, considering the limited availability of farmable land [1]. In agricultural engineering, cutting represents a main technique and determines substantially the productivity and efficiency of agricultural machinery (Figure 1).

Agricultural cutting tools are exposed to a high amount of wear. Wear changes the blade geometry and affects the energy efficiency and cutting quality significantly. Frequent regrinding leads to machine breakdowns and derogates the productivity during harvesting. Additionally, the regrinding reduces the durability of the costly knives. Harvesting machinery is limited in performance (even up to $1000 \mathrm{BHP}$ ), so that the additional required performance caused by blunt knives leads to a reduction of crop throughput. Harvesting is slowed down which reflects on higher opportunity costs [2]. The blade sharpness is the decisive factor in regard to the cutting energy. A blunt knife with a larger cutting edge radius increases the cutting energy considerably. A rise of $0.3 \mathrm{~mm}$ of the cutting edge radius causes an increase of the cutting energy by $100 \%$ [3]. New basic materials, heat and surface treatments, coatings, and innovative blade designs are intended to increase the durability and wear resistance of agricultural cutting tools. Field tests are executed to determine the edge holding property and energy efficiency of cutting tools. Varying soil and weather conditions restrict the repeatability and comparability of field tests. Otherwise, field tests provide realistic wear pattern in contrast to many common wear test methods. Common test methods either use standardized test specimen and do not consider the blade 

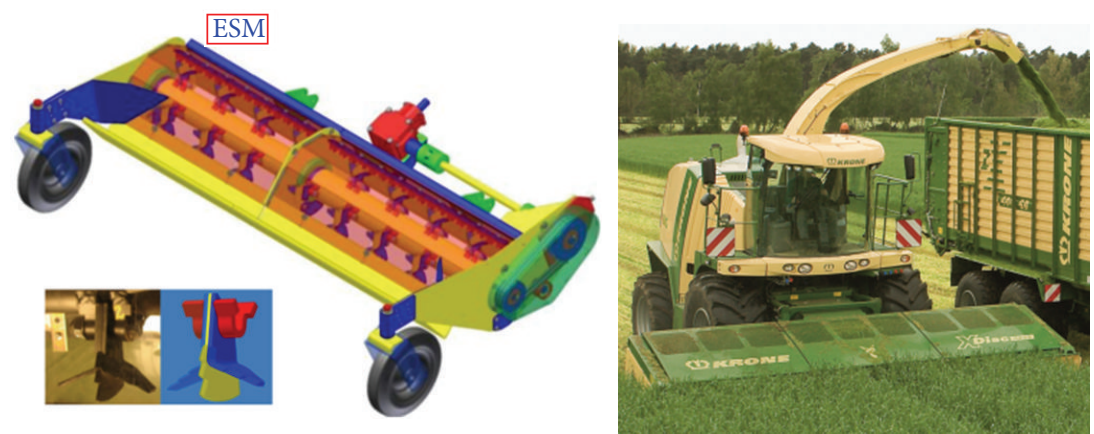

FIGURE 1: Flail mower head, field chopper.
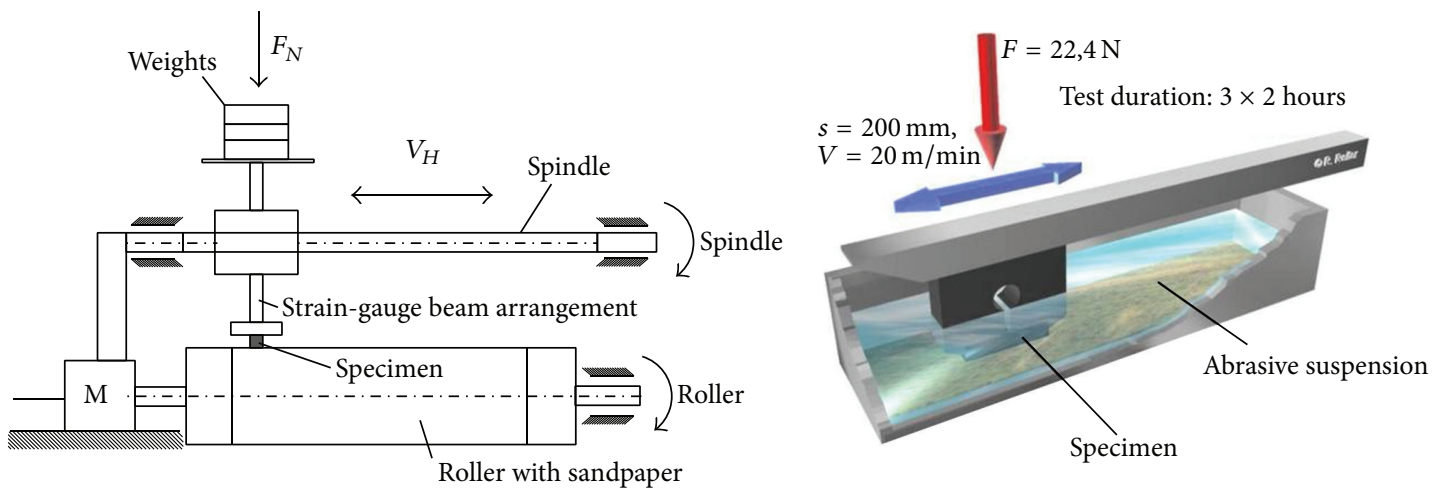

FIgure 2: Pin-on-belt test, Miller test $[4,5]$.
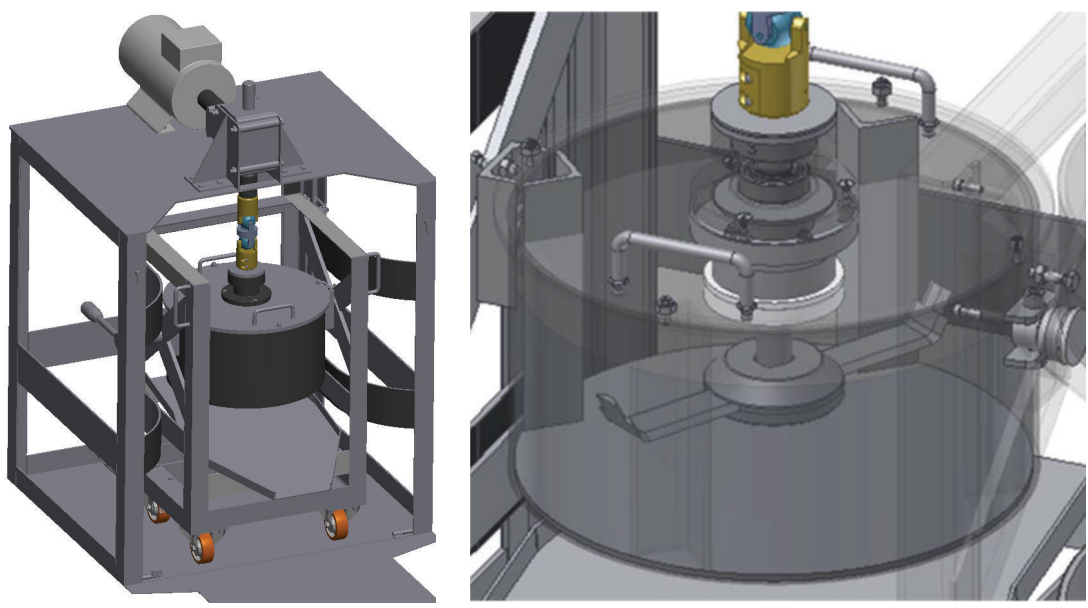

FIGURE 3: Novel test rig, slurry pot.

geometry or reproduce wear at low velocities (Figure 2) $[4,5]$. Furthermore, a consistent and adequate wear analyzing method for agricultural cutting tools does not exist up to now.

\section{The Novel Test Rig}

A new test rig has been built to compare the wear resistance and durability of different agricultural cutting tools (Figure 4) under repeatable and comparable test conditions while reproducing a realistic wear pattern.

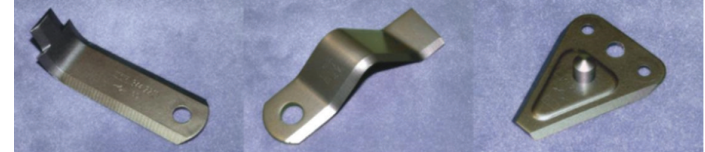

FIgURE 4: Different cutting tools of a high speed preflail chaff cutter.

The newly developed test bench consists of an outer frame and a slurry pot containing the abrasive media in which a pair of blades rotates (Figure 3). The slurry pot has an inner 
diameter of $370 \mathrm{~mm}$ and a volume of around 21.5 liters. The blades are attached to a shaft driven by an electrical engine. A homogeneous sand-gravel-water mixture serves as the abrasive media.

Considering the high impact velocities in operation, a high rotational speed is applied (around $15 \mathrm{~m} / \mathrm{s}$ ) to realistically reproduce the interactions between sand, gravel, and the blade surface. The particle shape and size distribution of the sand and gravel are standardized. The test parameters (ratio of components, rpm, test duration, etc.) are calibrated by preliminary tests. The focus of the preliminary tests is to minimize the effects of a decreasing abrasiveness of the sandgravel mixture during the test duration. The calibrated test parameters provide a constant and stable abrasiveness during the full test duration. The same pair of blades is tested while exchanging the filling of the slurry pot repetitively with new abrasives within a definite time interval. Furthermore, tests have been conducted in which the pair of blades is exchanged without changing the mixture of abrasives. The blades show very little differences in the progression of wear which indicates a high degree of repeatability and comparability of the test method.

A very similar wear pattern has been received compared to the wear pattern obtained in field tests. This is the result of a similar reproduction of the wearing process in the test rig compared to the wearing process of agricultural cutting tools under field operation. In the field, as well as in the test rig, especially when operating at ground level, the high impact velocities in the interactions of the blade with the soaked up sand and gravel generate the largest proportion of wear.

\section{Analyzing Methods}

An integral part for the advancement and optimization of agricultural cutting tools is a clear and consistent method to determine the wear resistance, the edge holding property, and the energetic efficiency. Currently, there is no standardized analyzing method. Methods derived from the machine tool manufacturing industry are applied, which are neither standardized, technically mature, nor suitable for the agricultural field of application.

The determination of the weight loss [6] and the decrease of the blade width [7] are relatively simple wear analyzing methods. The weighting of the knives and the determination of the blade width, before and after the wear test, provide a quantitative wear conclusion. They do not consider the edge holding property or the energy efficiency. A common analyzing method is the characterization of the cutting edge with a cutting edge radius (Figure 5) [8]. For that purpose, the cutting edge is approximated with a circle. The radius is a degree of the wear rate and the edge holding property. Different approaches exist for the circle approximation. It is possible to approximate with a minimum enveloping circle, a maximum inscribed circle, a Tschebyscheff circle, or various so-called best-fit methods [9]. The most prevalent methods are based on either algebraic or geometrical leastsquare methods [10]. Depending on the selected approach for the circle approximation and the algorithm for the bestfit method, significant differences occur. The cutting edge approximation by a minimum enveloped circle results in a different radius compared to an approximation with a maximum inscribed circle (Figures 5(a) and 5(b)). The lack of a consistent standardized method leads to different results for the same cutting edge geometry. Moreover, it is possible to obtain the same radius for different cutting edge geometries (Figure 5(c)).

By using a circle, only cutting edges with an ideal rounding can be described precisely. In reality, a cutting edge consists of different circular arcs. Consequently, the entire cutting edge contour cannot be described with only one radius. By overlapping and covering the cutting edge in its original condition with the worn-out cutting edge profile, the quantity of removed material can be determined (Figure 6(a)).

The $K$-factor model originates from the tool manufacturing industry and is applied to describe the defined rounding of metal cutting tools [11]. To determine the $K$-factor, the flanks of the blade are tangentially extended (Figure 6(b)). $S \alpha$ and $S \gamma$ are the distances between the separation points $P \alpha$ and $P \gamma$ and the intersection of the extension lines. The separation points $P \alpha$ and $P \gamma$ are the points in which the line goes into a rounding. The $K$-factor is defined as $K=S \gamma / S \alpha$ and describes whether the rounding tends to one side or the other. The $K$-factor model also contains the parameters $S q$ and $\Delta r . S q$ is the mean value of the distances $S \alpha$ and $S \gamma$ and describes a quantitative degree of the rounding. $\Delta r$ is the distance between the intersection point of the extension lines and the highest point of the cutting edge profile and indicates the sharpness of the rounding.

The $K$-factor model is designed for an ideal rounding. It does not consider whether and how much the cutting edge profile deviates from an ideal arc circle geometry. Accordingly, it is incapable of describing the effective edge holding property and energy efficiency. Further, the $K$-factor model is strongly dependent on a stable calculation of the tangential extensions. Due to small wedge angles and highly irregular profiles of worn-out knives, this is not always possible.

\section{Ellipse-Fit Method}

A 3D measuring device from GFMesstechnik (GFM MIKROCAO LITE) is used to measure the blade geometry. The 3D sensor projects fringe patterns of parallel stripes onto the object surface. A camera records the perspective deformation so that the height values for any single surface point are gained from the gray value slopes of the phase shifted fringe patterns. $2 \mathrm{D}$ cutting edge profiles are extracted out of the $3 \mathrm{D}$ data (Figure 7(a)). The cutting edge profile is sectioned into a line-rounding-line geometry by separation points. A least-square line is fitted into the flanks of the cutting edge. When the deviation exceeds a specific boundary value, the separation point is set in which the line goes into a rounding.

To characterize and interpret the rounding, an ellipse is fitted by using an ellipse-specific direct least-square fitting algorithm proposed by Fitzgibbon et al. [12]. Fitzgibbons ellipse-fit algorithm is ellipse specific and noniterative, has a low eccentricity bias, and is relatively robust to noise.

The ellipse can be defined by the radiuses of the semiaxes $a$ and $b$ and the angle $\vartheta$ (Figure $7(b)$ ). To describe the cutting 


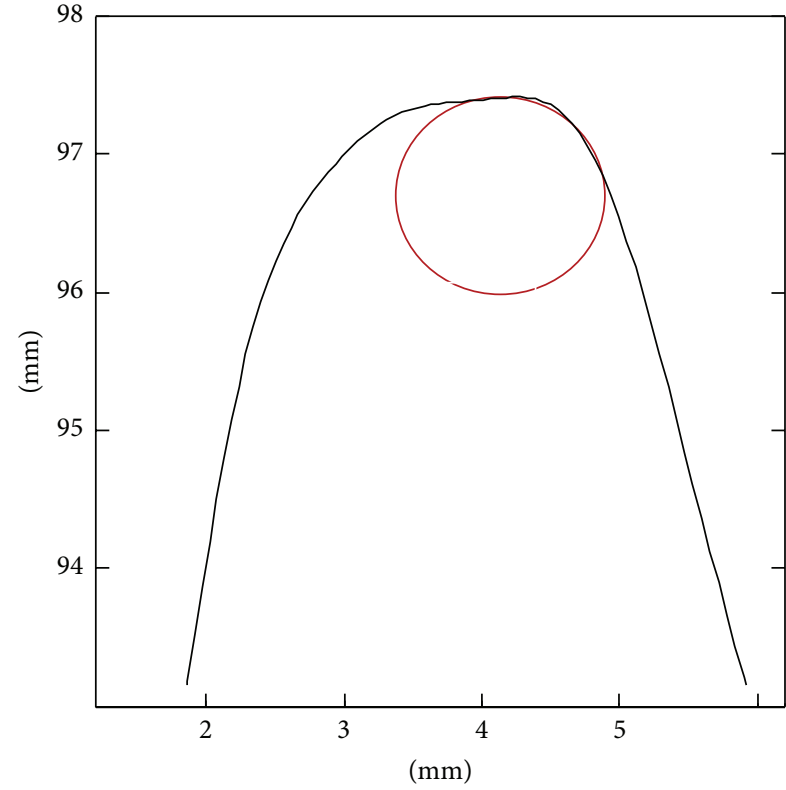

(a)

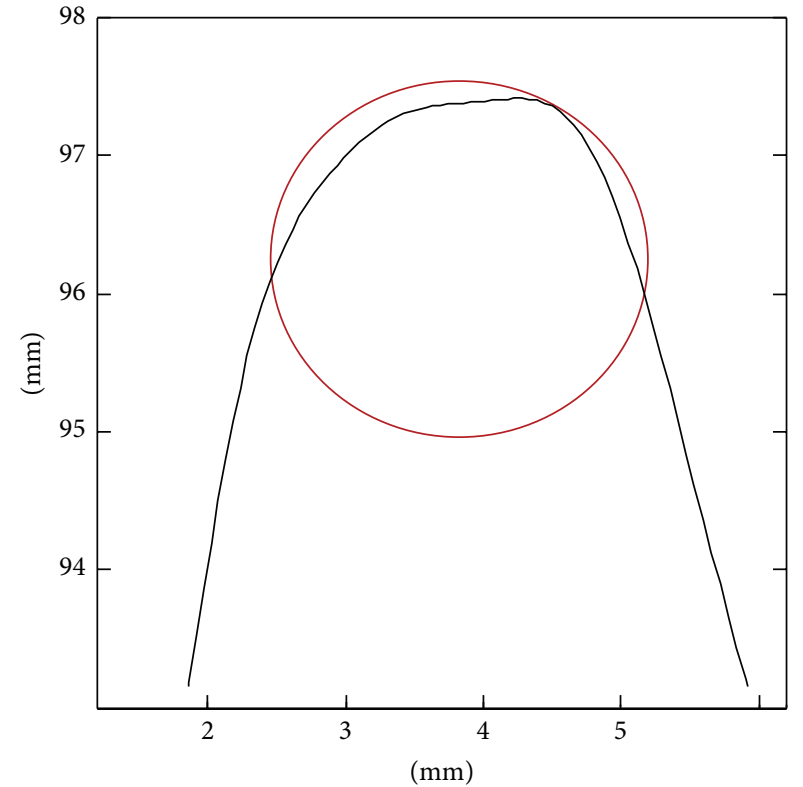

(b)

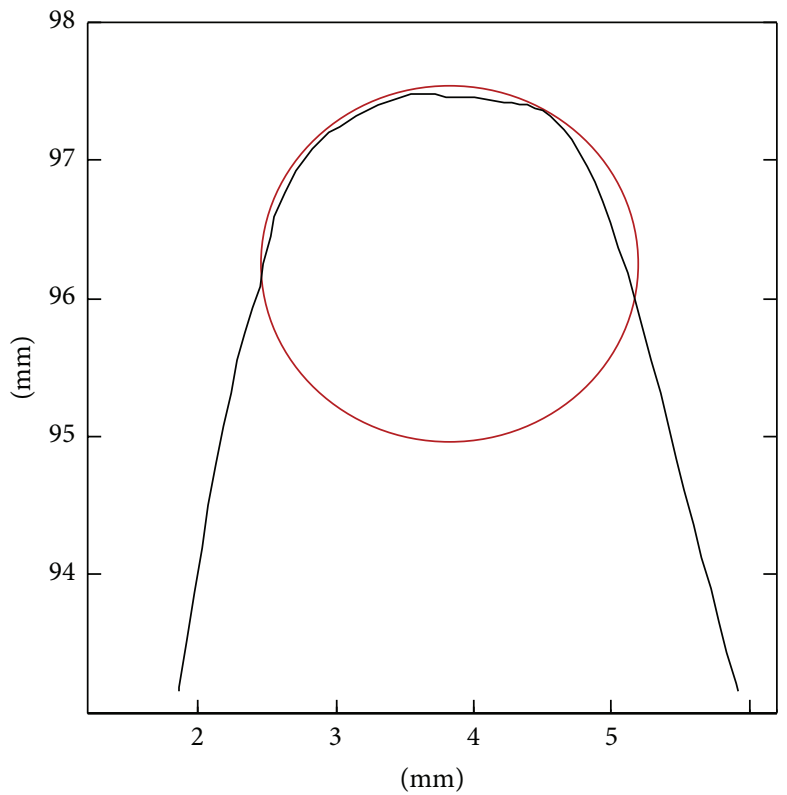

(c)

FIGURE 5: Characterization of the cutting edge with the cutting edge radius.

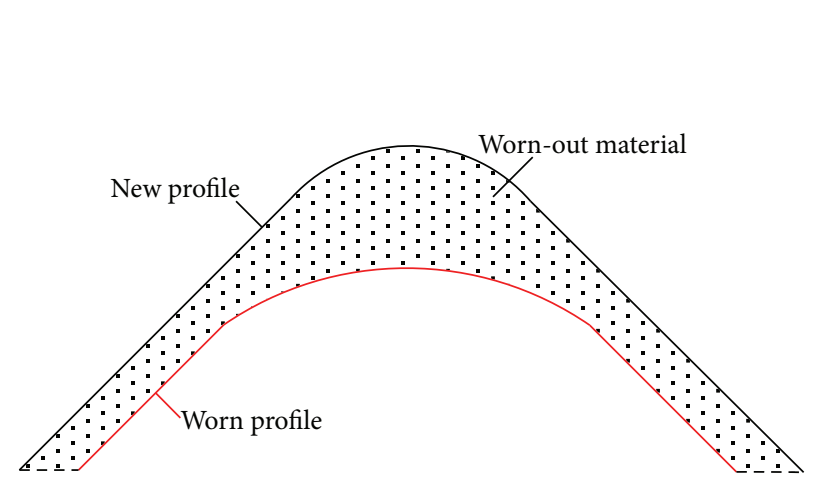

(a)

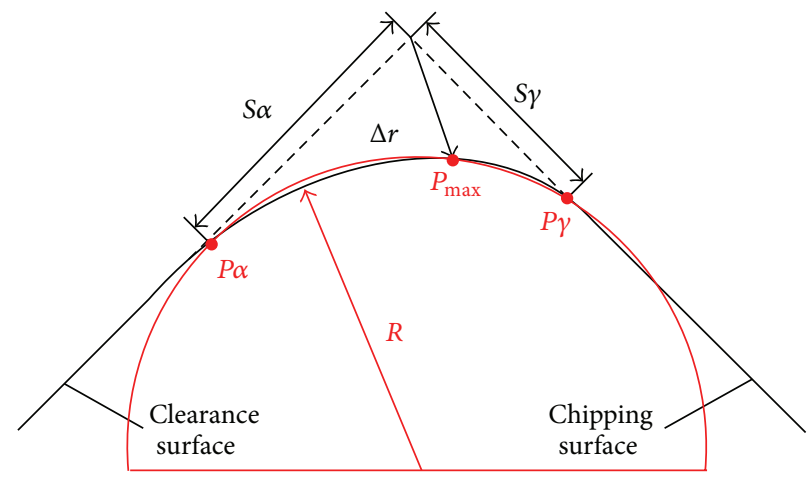

(b)

Figure 6: (a) Wear characterization by determination of the material abrasion and (b) the $K$-factor model. 


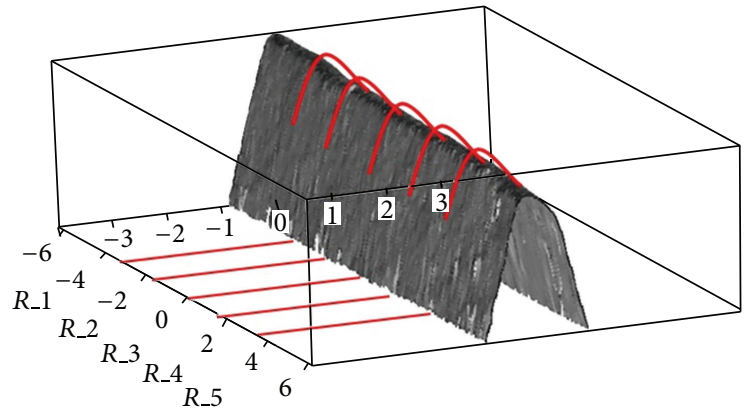

(a)

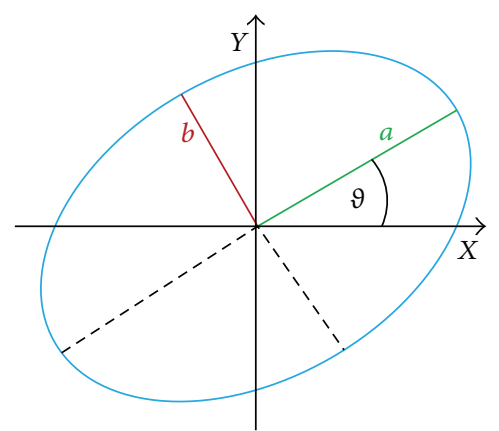

(b)

FigURE 7: 3D geometry of a cutter blade and parameters of an ellipse.

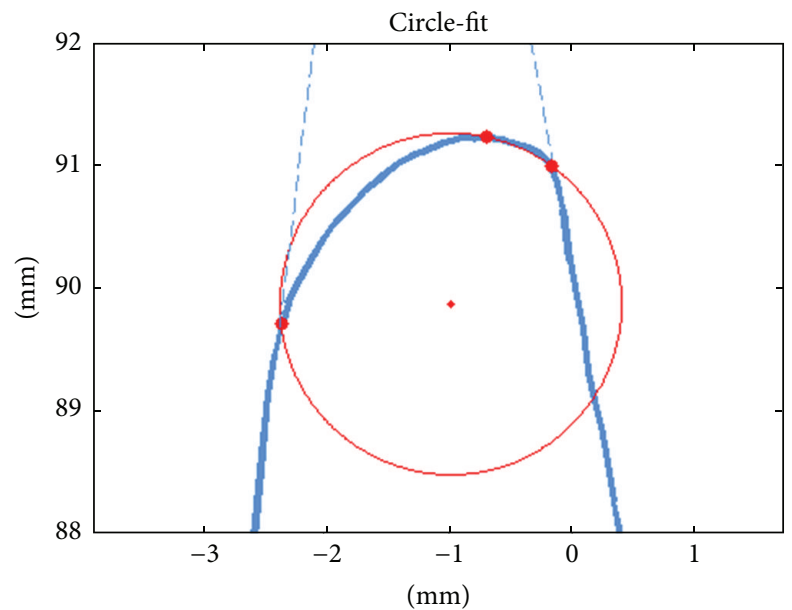

Cutting edge radius: $1.37 \mathrm{~mm}$

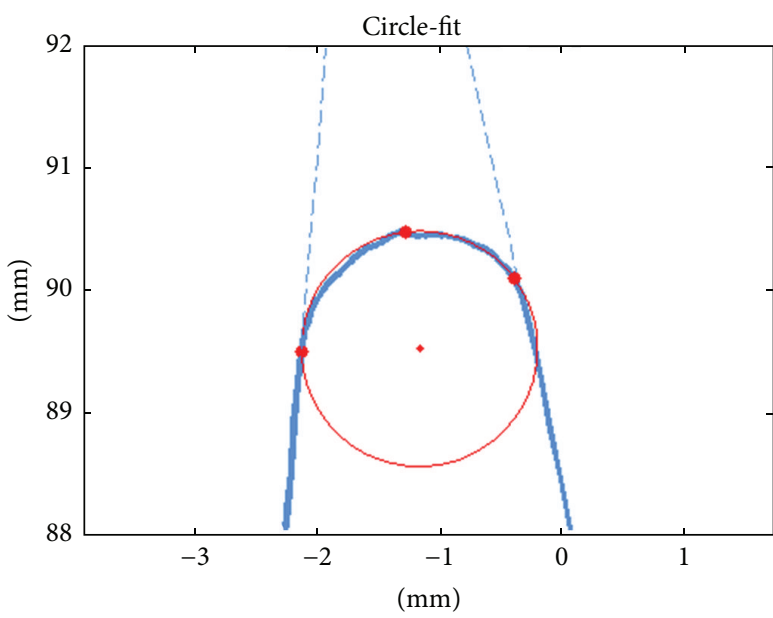

Cutting edge radius: $0.96 \mathrm{~mm}$

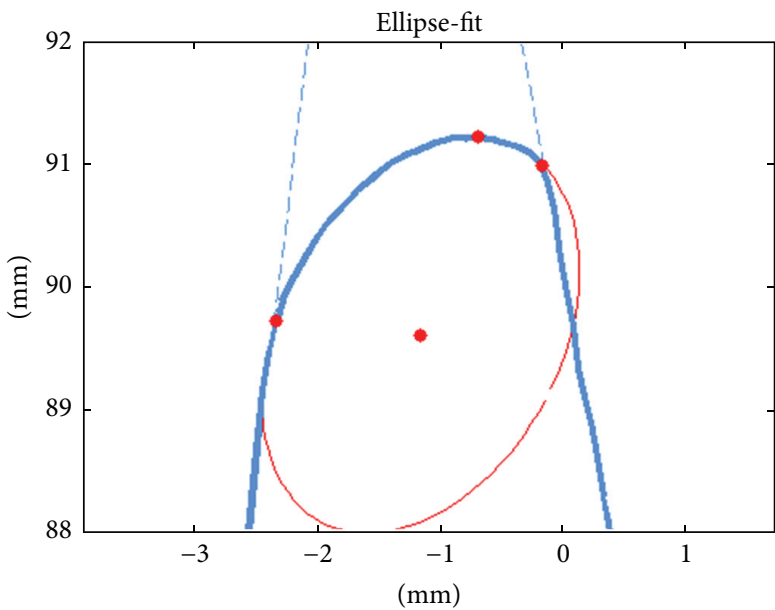

Substitution radius: $1.26 \mathrm{~mm}$

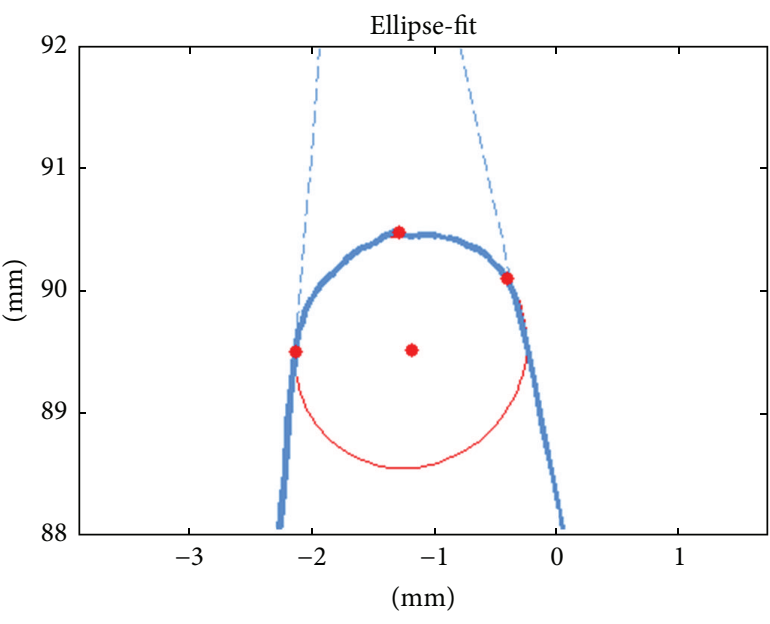

Substitution radius: $0.95 \mathrm{~mm}$

Figure 8: Comparison between circle-fit and ellipse-fit.

edge, the parameters are integrated into a substitution cutting edge radius (1). The two semiaxes are not exposed to the cutting at equal measure. Therefore, the semiaxes are weighted with the angle $\vartheta$. Sine and cosine are squared to decrease the weighting of the semiaxis which is less exposed to the cutting:

Substitution radius $r=a * \cos ^{2} \vartheta+b * \sin ^{2} \vartheta$.
A comparison of different cutting edges with a circle-fit and ellipse-fit approximation is shown in Figure 8.

With Ansys CFX, numeric flow simulations of different ellipse geometries have been conducted (Figure 9). The effects of the shape and thus the proportion of the diameters and the angle and position of the ellipse and their relation to the energetic efficiency were subject of the investigations. 


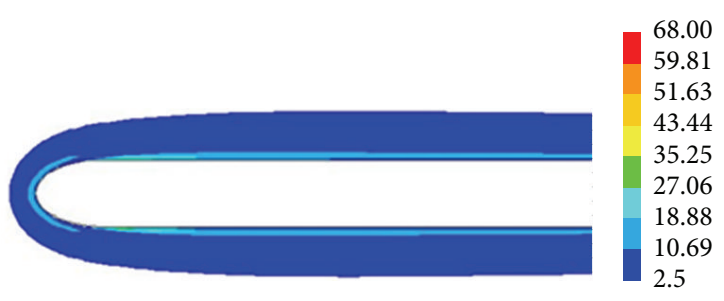

Contours of turbulent kinetic energy $(\mathrm{k})\left(\mathrm{m}^{2} / \mathrm{s}^{2}\right)$

Ansys fluent 13.0 (2d, pbns, rke)

(a)

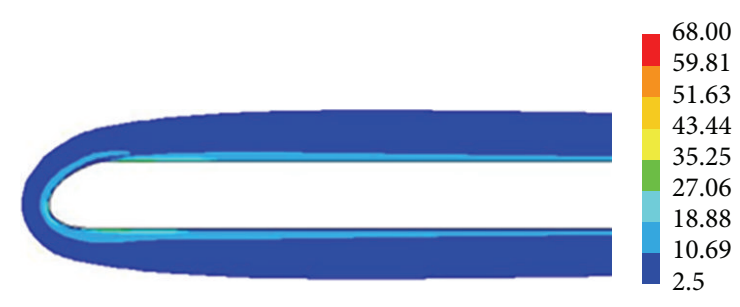

Contours of turbulent kinetic energy $(\mathrm{k})\left(\mathrm{m}^{2} / \mathrm{s}^{2}\right)$

Ansys fluent 13.0 (2d, pbns, rke)

(b)

Figure 9: CFD simulations of different ellipse geometries.

Theoretical conclusions concerning the energy efficiency have been drawn by calculating the drag coefficients of different ellipse geometries. A degree of correlation has been found, comparing the calculated drag coefficients with the results of the substitution radius. Similar to the drag coefficient calculations, the form and the shape of the ellipse (weighting of the diameters with the angle $\vartheta$ ) are considered in the substitution radius. Thus, the substitution radius presented in this paper characterizes more reasonably and precisely the energetic efficiency of agricultural cutting tools than conventional characterization methods. Experiments to validate the theoretical investigations have yet to be conducted. For this purpose, the input power and engine torque can be measured while rotating knives with a defined rounding in the test rig.

\section{Conclusion}

The test bench provides wear pattern similar to field tests. Concurrently, repeatable and comparable results are generated under laboratory conditions in a short period of time. In combination with the ellipse-fit method, the energy efficiency and edge holding property of agricultural cutting tools can be characterized more accurately and reasonably than conventional characterization methods. A potential characterization of the energetic efficiency by the presented substitution radius has been theoretically evaluated by numeric flow simulations. Validation experiments have yet to be conducted.

The substitution cutting edge radius enables the comparison of the wear resistance of different cutting tools with one representative parameter. The newly developed test and analyzing method can build the foundation for a more rapid and efficient optimization of agricultural cutting tools.

\section{Conflict of Interests}

The authors declare that there is no conflict of interests regarding the publication of this paper.

\section{References}

[1] ADM Germany GmbH, Statistische Informationen zum Getreide- und Futtermittelmarkt, 2014, http://www.acti.de.

[2] K. J. Wild, V. Walther, and J. K. Schueller, "Optimizing fuel consumption and knife wear in a self-propelled forage chopper by improving the grinding strategy," in Proceedings of the American Society of Agricultural and Biological Engineers Annual International Meeting, pp. 5899-5916, Reno, Nev, USA, June 2009.

[3] Landtechnik 55, Häckslermesser und Gegenschneide eines Feldhäckslers, 2000.

[4] ASTM Standard G65; 2004, Standard Test Method for Measuring Abrasion Using the Dry Sand/Rubber Wheel Apparatus, ASTM International, West Conshohocken, Pa, USA, 2010, http://www .astm.org/.

[5] H. Czichos and K.-H. Habig, Tribologie-Handbuch, chapter 1, Vieweg+Teubner, Wiesbaden, Germany, 3rd edition, 1991.

[6] J. Kurzynski, Entwicklung eines Verfahrens und Ermittlung von Werkstoffkennwerten für eine Beanspruchungsgerechte Auswahl verschleißbeständiger Stähle, Forschungsbericht, Verlag und Vertriebsgesellschaft, Düsseldorf, Germany, 1999.

[7] J. Fehrmann, G. Bernhardt, M. Flanhardt, and A. Achimas, "Standzeiterhöhung der Werkzeuge bei der Strohzerkleinerung durch Optimieren von Werkzeugform, Werkstoff und Materialbehandlungsverfahren," in VDI/MEG-Tagung Landtechnik Hannover 4-5, November 2005, VDI-Berichte 1895, pp. 425-433, Düsseldorf VDI, 2005.

[8] A. Heinrich, Grundlagen für ein Messsystem zur Bestimmung des Verschleißzustandes des Häckselaggregates eines Feldhäckslers, TUDPress, 2007.

[9] T. S. R. Murthy, "A comparison of different algorithms for circularity evaluation," Precision Engineering, vol. 8, no. 1, pp. 19-23, 1986.

[10] P. Sturm and P. Gargallo, "Conic fitting using the geometric distance," in Computer Vision-ACCV 2007, Y. Yagi, S. B. Kang, I. S. Kweon, and H. Zha, Eds., vol. 4844 of Lecture Notes in Computer Science, pp. 784-795, Springer, Berlin, Germany, 2007.

[11] F. Tikal, Schneidkantenpräparation-Ziele, Verfahren und Messmethoden: Berichte aus Industrie und Forschung, Kassel University Press, Kassel, Germany, 2009.

[12] A. W. Fitzgibbon, M. Pilu, and R. B. Fisher, "Direct least squares fitting of ellipses," in Proceedings of the 13th International Conference on Pattern Recognition (ICPR '96), pp. 253-257, Vienna, Austria, August 1996. 

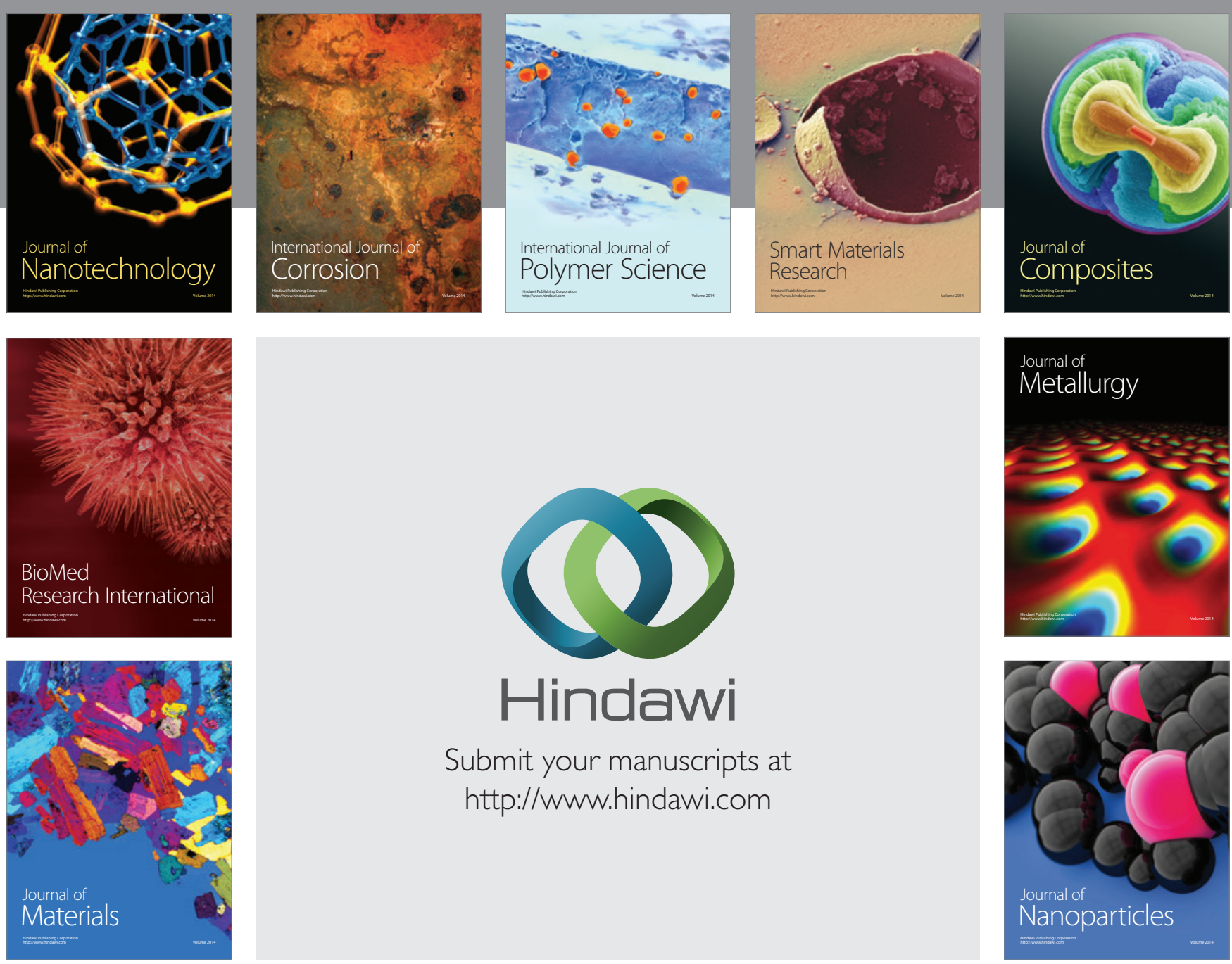

Submit your manuscripts at http://www.hindawi.com
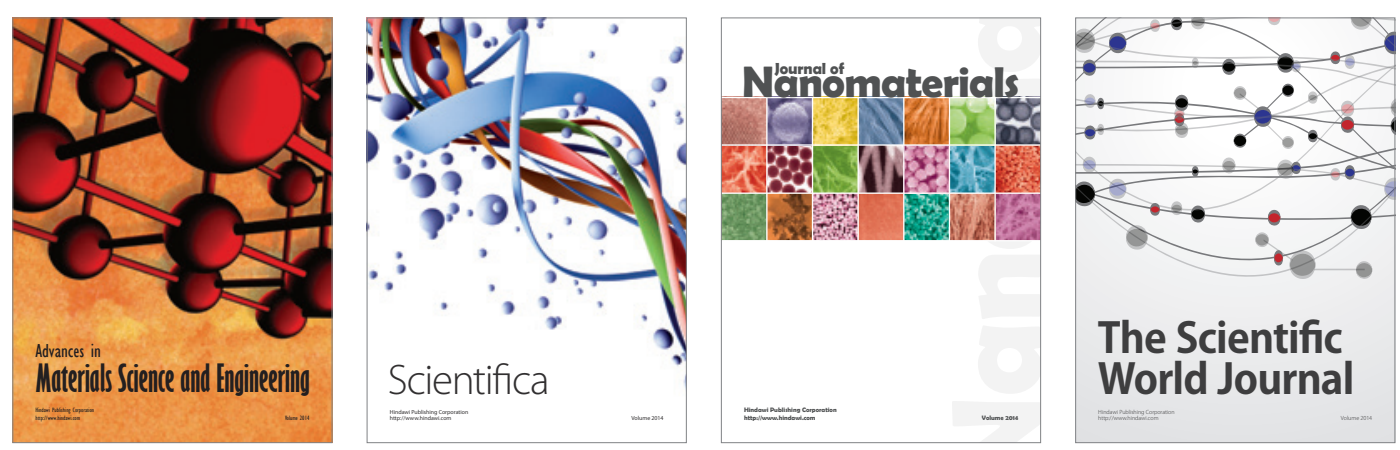

\section{The Scientific World Journal}
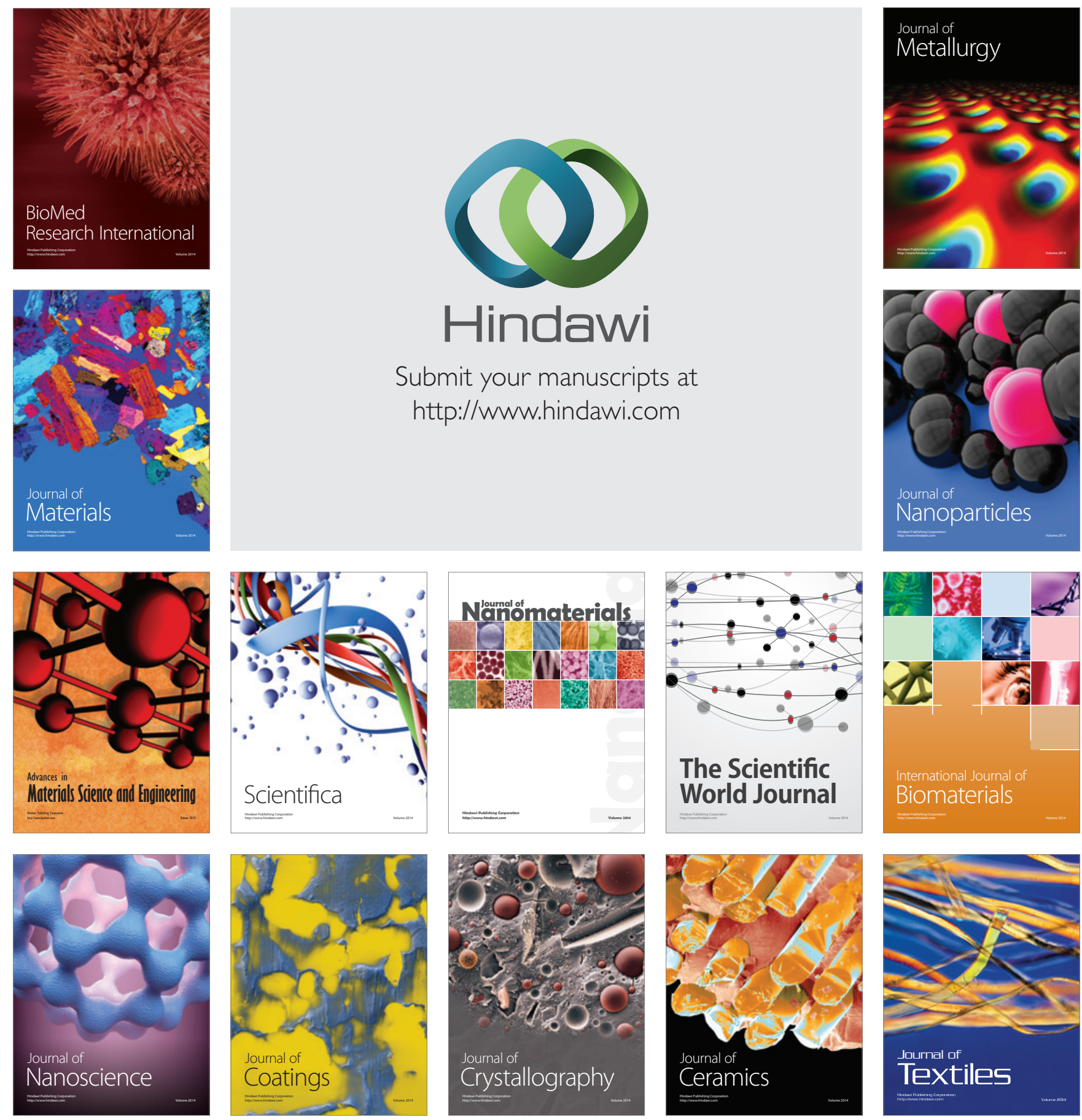